\title{
Studies on zinc recovery from technogenic waste
}

\author{
Marinela Panayotova ${ }^{1, *}$, and Vladko Panayotov ${ }^{1,2}$ \\ ${ }^{1}$ University of Mining and Geology, 1700 Sofia, Bulgaria \\ ${ }^{2}$ Bulgarian Academy of Sciences, 1000 Sofia, Bulgaria
}

\begin{abstract}
Results from laboratory experiments are presented on extraction of zinc available in waste from lead-zinc metallu[rgy, mixed with lead-zinc flotation tailings and some waste rock, by leaching it under atmospheric conditions with sulfuric acid $\left(\mathrm{H}_{2} \mathrm{SO}_{4}\right)$ solutions (5 and 10 wt. \%) and $30 \%$ hydrogen peroxide in the temperature range of $25-80^{\circ} \mathrm{C}$, at leaching time 30 - 120 min. Material leaching with $10 \% \mathrm{H}_{2} \mathrm{SO}_{4}$ solution at $70{ }^{\circ} \mathrm{C}$ for one hour brings into pregnant leach solution (PLS) around $80 \%$ of zinc available. Imposing an electrochemical impact during the leaching process increases the quantity of leached zinc by around $5 \%$. Direct electrowinning from the PLS obtains zinc metal of grade $75-76 \%$. The suggested treatment removes metals-pollutants from accumulated mixed technogenic waste therefore rendering it more environmentally friendly. Experiments showed that old mixed waste from mining, mineral processing and metallurgy activities merits further studies as secondary source of metals.
\end{abstract}

\section{Introduction}

Zinc is used mainly in preparing galvanic coatings for steel protection from corrosion, production of brass and bronze, zinc-based alloys and different chemical compounds. A small decrease in zinc mine production and zinc consumption was estimated for 2020 due to the COVID 19 pandemics [1]. Since nearly two-thirds of zinc containing materials are used in the construction and infrastructure sectors [2] it is expected that with the world revival prom the COVID 19 the need of zinc will increase again. A demand growth of $2.2 \%$ from 2018 to 2023 is expected [2].

Zinc is used also in the renewable energy technologies: galvanized steel is employed in solar panel frames, wind turbines, hydro-electric plants and distribution poles. Zinc is the main anode materials in the different large rechargeable zinc batteries that secure constant power supply from non-constant sources, such as wind and solar power [3]. Especially in thin film using industries, such as solar panels technologies, zinc oxide $(\mathrm{ZnO})$ can substitute some semiconductors. Amorphous transparent conductive oxides, such as zinc-tin-oxide, indium-zinc-oxide and gallium-indium-zinc-oxide exhibit promising properties, comparable or even better than indium-tin-oxides. Their commercialization is estimated to start in the next 5-7 years [2].

\footnotetext{
*Corresponding author: marichim@mgu.bg
} 
Due to its recyclability and durability zinc contributes to the construction of sustainable buildings.

Zinc is produced from zinc ores or polymetallic ores. Initially zinc concentrate is obtained by beneficiation technologies. A concentrate containing zinc sulfide is produced from sulfide ores. The concentrate is often processed by a pyrometallurgical technology where zinc is fumed and condensed as zinc oxide that is further processed by dissolution, purification of the solution, and electrowinning. The roast-leach-electrowinning (RLE) process is applied also as standard process for processing zinc sulfide concentrate. In this process, zinc sulfide is oxidized to form zinc oxide that is acid-leached. Zinc metal is produced by electrolysis, after purification of the obtained solution. RLE has been applied more widely and is the most popular process for the present. Both processes produce sulfur dioxide as byproduct that is converted to sulfuric acid to avoid air pollution [4].

Hydrometallurgy processes for producing zinc avoids the roasting step of the RLE by directly dissolving zinc that is available in the sulfide minerals. The following stages are purification and electrolysis. Zinc sulfide (and at higher degree zinc oxide) minerals are leachable in a different solutions based on sulfuric (including ferric ions in sulfate solution) and chloride media. Sulfuric acid media are cheaper, chloride media are corrosive and require more expensive equipment. As a result sulfate leaching for zinc recovery has received wider commercial application.

The direct leaching of zinc sulfide ores can be divided into atmospheric stirred tank leach process (for example, Outotec and Union Minière technology), pressure leach (Dynatec Zinc pressure leach technology) and percolation leach (Geocoat and Teck Cominco's HydroZinc process) options. It has been found that introduction of oxygen into atmospheric stirred tank leach process, where solution containing ferric ions is used [4] or into pressure sulfuric acid leaching system [5], enhances zinc leaching by regenerating ferric ions.

Zinc is metal whose recycling is developed. For example, in 2020 one-third of the refined zinc obtained in the United States was produced from secondary materials, such as crude zinc oxide obtained from electric arc furnace dust and galvanizing residues [1]. In general, zinc smelters use 10-15\% secondary raw zinc-containing materials into their production processes [2].

However, recycling of metal products, even together with processing of metal-rich ores, can not ensure in future the needed metals. Processing of low-grade and complex ores, as well as mining, mineral-processing and non-tackled until now metal-production waste would help in this direction.

Diverse beneficiation studies have been carried out to obtain concentrates meeting the metallurgy requirements from low grade complex polymetallic ores [6 - 8].

Different hydrometallurgical routes have been proposed (but not entirely implemented commercially) to process complex sulfide ores that could not be economically processed through the RLE or pyrometallurgical processes.

Various leaching reagents were tested, such as sulfuric acid, sulfurous acid, ammonium hydroxide and sodium hydroxide and good results were obtained with sulfuric acid and with caustic soda at high enough concentration $[9,10]$. Sulfuric acid leaching followed by solvent extraction purification and electrowinning proved a suitable technology for extracting zinc from zinc oxide ore (10 -14 wt. \% zinc) containing iron (21-23 wt. \%) and manganese (1.5 5.6 wt. \%) as main other metals [10,11]. Citric acid [12] and ammonia-citric-acid-water [13] systems were also studied. However, in these systems, if the material to be leached contains copper, it could interfere with zinc leaching.

Numerous studies have been carried out to recover zinc from electric arc, blast, and converter furnaces dust from steelmaking industry. Ammonia/ammonium salt systems have been mainly utilized [14 - 16] but also dilute sulfuric acid [17]. 
The need for metals has led to a demand for technologies for their extracting from other technogenic waste, such as slag from plants smelting lead and zinc, solid wastes (sludge and slag) from iron- and steelmaking plants, copper converter slag, flotation tailings, disposed mill tailings of sulfide ores, magnetite concentrates, pyrrhotine concentrates [18 - 21], low grade zinc concentrate obtained by flotation of gathered flotation tailings [22], land filled Znrich sludge and jarosite [23].

Huge amounts of such types of waste are available worldwide. For example, the tailing dam of Kooshk lead-zinc industry (Iran) contains nearly 5 million tons of sphalerite tailings bearing $3.67 \%$ zinc but also high amount of pyrite [22]. Another example - the accumulated in Kazakhstan 10.1 billion tons of wastes from production of non-ferrous metals, combined with annual generation of 700 million tons of industrial wastes [24].

The recovery of metals from technogenic waste has a double beneficiary effect with respect to the environment - decreasing depletion of natural resourced, combined with less energy spending and avoiding leaching by rain water and emitting hazardous pollutants to the surroundings.

Having in mind a) expected increased need of metals, b) necessity to use impoverished and complex ores, c) above-mentioned studies on zinc extraction from secondary raw materials, and d) availability of mining waste in Bulgaria, we have decided to investigate the possibility to extract zinc from such technogenic waste. Based on the findings of the referred to studies and our experience, we have tested material leaching mainly with sulfuric acid solution.

\section{Materials and methods}

Laboratory experiments were carried out with material taken from an old site where waste from lead-zinc metallurgy, when disposed, was mixed with lead-zinc flotation tailings and some waste rock. The production activities were stopped 30-40 years ago and "natural restoration" took place. Except that the material could pose environmental and health problems, it could be a technogenic source of some basic metals, especially of zinc, as it turned out. The material contained in wt. $\%: 12.3 \% \mathrm{Zn}, 11.6 \% \mathrm{Fe}, 1.5 \% \mathrm{~Pb}, 0.5 \% \mathrm{Cu}$. The material was subjected to X-ray analysis (made with BRUKER D2 Phaser, Cu/Ni radiation).

In an effort to separate zinc-bearing minerals magnetic separation, as well as sulfide flotation aided by some modifications were attempted, however, unsuccessfully.

The material was subjected to milling to achieve $>90 \%$ particles with size $80-100 \mu \mathrm{m}$. The leaching was carried out batchwise in $3 \mathrm{~L}$ glass vessel (Figure 1). A possibility was ensured for heating, mechanical stirring (with a glass blade), and an electrochemical impact applying. The electrochemical impact was realized by introducing stainless steel electrodes in the suspension $\left(\mathrm{S}_{\mathrm{a}}=\mathrm{S}_{\mathrm{c}}\right)$ at direct current density of $2 \mathrm{~mA} / \mathrm{cm}^{2}$. Electrodes and the rectifier were removed in experiments without electrochemical impact.

The material used in each batch was $300 \mathrm{~g}$. Sulfuric acid and hydrogen peroxide used were of p.a. grade. Solutions were prepared with distilled water. After leaching and solid / liquid separation the copper was removed from the pregnant leach solution (PLS) by precipitation with potassium ethyl xanthate. Then the purified PLS was subjected to direct electrowinning for 2 hours at direct current density of $50 \mathrm{~mA} / \mathrm{cm}^{2}$ (following [25] and [7]). In the electrowinning experiments cathode was made of aluminium and anode was made of lead-silver alloy $(0.7 \mathrm{wt} \% \mathrm{Ag})$. A stabilized laboratory rectifier having inbuilt ampere-meter was used as an energy source. $\mathrm{pH}$ was measured by a laboratory $\mathrm{pH}$-meter. The deposited on cathode material was collected, dissolved (in aqua regia) and analyzed. Metals concentrations were determined by ICP-analysis. All experiments were conducted in duplicate (in triplicate for the electrochemically aided dissolution and direct electrowinning) and averaged values are presented. 


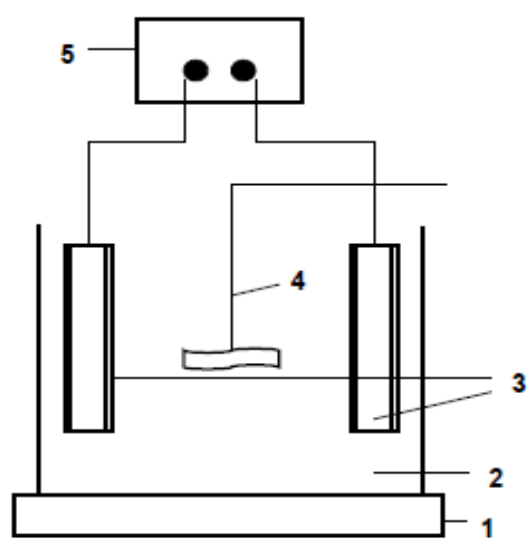

Fig. 1. Experimental set up: 1 - heater, 2 - reactor, 3 - electrodes, 4 - stirrer, 5 - laboratory rectifier.

\section{Results and discussion}

The X-ray diffraction (XRD) pattern of the studied material is presented in Figure 2. According to XRD study zinc presents as zincite, sphalerite, smithsonite and franklinite. The main gangue minerals are quartz and calcite. Iron presents as hematite, pyrite and small amounts of magnetite. Galena and chalcopyrite were found in very low amounts.

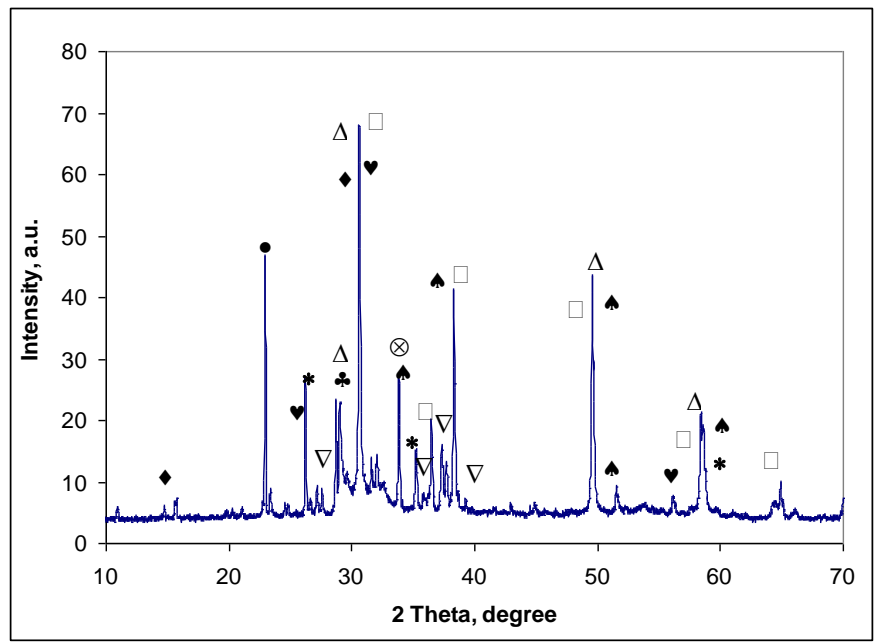

Fig. 2. X-ray diffraction pattern of the studied material: $\bullet \mathrm{CaCO}_{3}, \bullet \mathrm{SiO}_{2}, \bullet \mathrm{ZnCO}_{3}, * \mathrm{Fe}_{2} \mathrm{O}_{3}$, $\nabla \mathrm{FeS}_{2}, \Delta \mathrm{ZnS}, \propto \mathrm{ZnSO}_{4}, \square \mathrm{ZnO}, \otimes \mathrm{Fe}_{3} \mathrm{O}_{4}, \wedge \mathrm{ZnFeO}_{4}$

Based on the literature survey $[4,9,10,26]$, we have decided to study the effect of liquid to solid ratio ( $\mathrm{L}: \mathrm{S}=1,3,5$, and 7) with sulfuric acid as leaching reagent at $40{ }^{\circ} \mathrm{C}$. Results for two concentrations of $\mathrm{H}_{2} \mathrm{SO}_{4}$ are presented in Figure 3a. As it can be seen initially the zinc extraction increases with the amount of leaching reagent until reaching ratio $L: S=5$. The increase in zinc dissolution at $\mathrm{L}: \mathrm{S}=7$ is very small compared to that at $\mathrm{L}: \mathrm{S}=5$. That is why we have chosen the ratio $\mathrm{L}: \mathrm{S}=5$ in further experiments with that raw material. Similar ratio $(\mathrm{L}: \mathrm{S}=4)$ was found as optimum for extracting zinc from a rotary kiln cinder, 
where the used $\mathrm{H}_{2} \mathrm{SO}_{4}$ was $20 \%$ [27] and for low-grade zinc oxide ore where the used $\mathrm{H}_{2} \mathrm{SO}_{4}$ was $15 \%$ [7]

Sulfuric acid in the same concentrations (5 and $10 \%$ ) was used to study the effect of leaching time on the zinc extracted into the PLS. Results are shown in Figure 3b. Increasing the treatment time from 30 to 120 min ensures increased amount of leached zinc. However, since i) the big difference was observed between 30th and 60th minute and ii) the process continuation in time (which means higher energy for stirring) has not lead to considerable increase in the leached zinc, especially in the case where $10 \%$ acid was used, is could be assumed that $60 \mathrm{~min}$ is the optimum leaching time in this case. Other authors have also found 1 hour as optimum treatment time [7]. In addition, studies of Wang and coauthors [5] showed that when the leaching time was 1 hour considerably less amount of iron entered into the PLS, compared to 4 hours process.
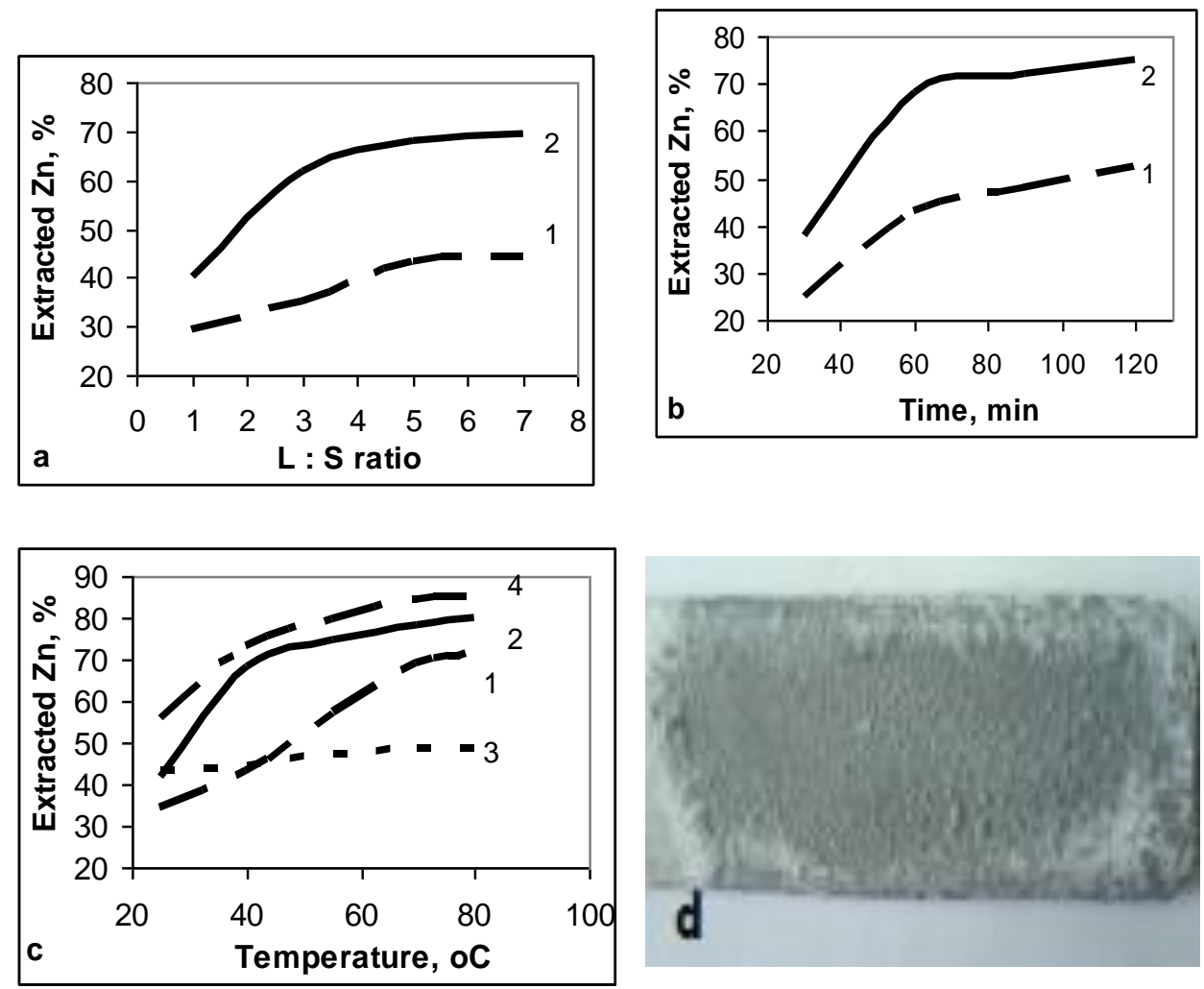

Fig. 3. Influence of leaching conditions on zinc extraction: a) effect of liquid to solid ratio $-40{ }^{\circ} \mathrm{C}$; b) effect of time - $40{ }^{\circ} \mathrm{C}$; c) effect of leaching solution: $1-5 \%$ solution of $\mathrm{H}_{2} \mathrm{SO}_{4}, 2-10 \%$ solution of $\mathrm{H}_{2} \mathrm{SO}_{4}, 3-30 \% \mathrm{H}_{2} \mathrm{O}_{2} ; 4-10 \%$ solution of $\mathrm{H}_{2} \mathrm{SO}_{4}$ with electrochemical impact; d) electrowon zinc from purified PLS obtained by leaching with $10 \%$ solution of $\mathrm{H}_{2} \mathrm{SO}_{4}$ at an electrochemical impact.

Effect of the concentration of used $\mathrm{H}_{2} \mathrm{SO}_{4}$ can be seen in Figures $3 \mathrm{a}-3 \mathrm{c}$. It is obvious that better results are obtained with $10 \%$ acid solution, compared to $5 \%$ solution. Increase in zinc extraction with increasing the concentration of used $\mathrm{H}_{2} \mathrm{SO}_{4}$ (up to 20 - 30 wt. \%) was observed also by other authors [10, 28, 29]. However, as it can be seen in Figure 3, good results are obtained even with $10 \% \mathrm{H}_{2} \mathrm{SO}_{4}$.

Figure $3 \mathrm{c}$ presents simultaneously the influence of temperature, the effect of use of another leaching reagent $\left(30 \% \mathrm{H}_{2} \mathrm{O}_{2}\right)$, as well as the influence of applied electrochemical 
impact while using $10 \% \mathrm{H}_{2} \mathrm{SO}_{4}$ as leaching solution. Tests with $\mathrm{H}_{2} \mathrm{O}_{2}$ were inspired by some positive reports on leaching of sulfide minerals [30,31]. Nevertheless, as it can be seen, despite the initial encouraging results at low temperature, the hydrogen peroxide solution is not a suitable leaching reagent for this material.

The results show that the electrochemical impact leads to an increase of about $5 \%$ in the leaching of zinc into the solution. This could be assigned to the facilitated dissolution (by the current) of the $\mathrm{ZnS}$ that present in the sample, since naturally the dissolution of $\mathrm{ZnS}$ is slower compared to the dissolution of $\mathrm{ZnO}$ [4]. In addition, a possible positive influence [32] could be expected of some ferric ions entering the solution due to anode corrosion and/or anodic oxidation of ferro-ions coming into solution from some iron-bearing minerals that present in the treated material.

Temperature increase leads to an increase in the leaching efficiency of $\mathrm{H}_{2} \mathrm{SO}_{4}$ solutions Figure $3 \mathrm{c}$. With the studied material, we could assume that the optimum temperature is 70 ${ }^{\circ} \mathrm{C}$, since the difference in zinc leaching at 70 and $80{ }^{\circ} \mathrm{C}$ is only $1-2 \%$. An increase in the leaching process effectiveness with the temperature raise for sulfuric acid based leaching media was observed also by other studies [26, 27, 33]. Optimal leaching temperature of 55 ${ }^{\circ} \mathrm{C}$ was obtained by Xiao and coauthors [27], however at use of $20 \%$ solution of $\mathrm{H}_{2} \mathrm{SO}_{4}$ and for $90 \mathrm{~min}$. Abdel-Aal [33] pointed $70{ }^{\circ} \mathrm{C}$ as optimal temperature where nearly $94 \%$ of zinc available in the materials were leached in $10 \% \mathrm{H}_{2} \mathrm{SO}_{4}$ for 2 hours. Li and coauthors [29] also found $70{ }^{\circ} \mathrm{C}$ as optimal temperature where nearly $92 \%$ of zinc available were leached with $10 \% \mathrm{H}_{2} \mathrm{SO}_{4}$ from zinc plant purification residue for only $20 \mathrm{~min}$, however at $\mathrm{L}: \mathrm{S}$ ratio of 50. On the other hand Soltani and coauthors [10] claimed $45^{\circ} \mathrm{C}$ as optimal to avoid increased leaching efficiency of impurities like manganese and iron, observed at $75^{\circ} \mathrm{C}$. The main side metals in our material are lead, iron and copper. In sulfuric acid medium lead precipitates as $\mathrm{PbSO}_{4}$ and remains in the solid phase. At the end of the leaching process the $\mathrm{pH}$ value of the PLS was in the range 5.3 - 5.5 most probably due to neutralizing effect of carbonates presenting in the material. Probably, this was the reason for the relatively low concentrations of iron (in the range $4-8 \mathrm{mg} / \mathrm{L}$ ) found in the PLS. However, the PLS contained cadmium $(67.8$ - $93.5 \mathrm{mg} / \mathrm{L})$ and copper $(33.4-42.7 \mathrm{mg} / \mathrm{L})$ and the latter could interfere with the direct electrowinning of zinc. This required copper ions precipitation and separation from the PLS by addition of potassium ethyl xanthate. The separated precipitate might be collected and used for copper regeneration.

Leaching of studied material for 60 min with $10 \% \mathrm{H}_{2} \mathrm{SO}_{4}$ solution at applied electrochemical impact and at $70^{\circ} \mathrm{C}$ resulted in PLS containing zinc in the range of 30797 $31298 \mathrm{mg} / \mathrm{L}$ (for 3 parallel experiments). This is at the low edge of concentrations suitable for direct electrowinning $[7,10]$. However, the concentration was not too low and practically in the absence of copper a possibility for direct zinc recovery on cathode was expected and tested. Averaged data from analysis of the solid phase obtained on cathode by direct zinc electrowinning are presented in Table 1 and the appearance of cathode is shown in Figure $3 \mathrm{~d}$.

Table 1. Results from the analysis of the electrowon zinc.

\begin{tabular}{|c|c|c|c|c|c|}
\hline Element & $\mathbf{P b}$ & $\mathbf{Z n}$ & $\mathbf{C u}$ & $\mathbf{F e}$ & $\mathbf{C d}$ \\
\hline Concn., wt. \% & 0.44 & 75.83 & 0.51 & 0.42 & 1.15 \\
\hline
\end{tabular}

As it can be seen from Table 1 and Figure $3 \mathrm{~d}$ the obtained solid material shows zinc content similar to that in very high quality zinc concentrate and can be directly send to zinc metallurgy. 


\section{Conclusions}

Based on the laboratory experiments carried out the following conclusions can be drawn:

It is possible to extract into solution zinc available in material representing old waste from lead-zinc metallurgy, mixed with lead-zinc flotation tailings and some waste rock, by leaching it under atmospheric conditions with 5 and $10 \%$ sulfuric acid solutions. Increasing the leaching temperature from 25 to $80^{\circ} \mathrm{C}$ and the leaching time from 30 to 120 min increases the amount of zinc entering the PLS.

It is possible to extract into solution around $80 \%$ of zinc available in that material by leaching it under atmospheric conditions with $10 \% \mathrm{H}_{2} \mathrm{SO}_{4}$ solution at $70{ }^{\circ} \mathrm{C}$ for one hour.

Imposing an electrochemical impact during the process of leaching with $10 \% \mathrm{H}_{2} \mathrm{SO}_{4}$ increases the amount of leached zinc by around $5 \%$.

Lead that presents in the studied materials is not leached. The leached copper can be removed from PLS by precipitation.

Direct electrowinning of zinc from the pregnant leach solution is possible, the grade of the electrowon metal is $75-76 \%$.

Besides zinc recovering from the waste material, the proposed treatment removes metalspollutants from that material thus rendering it more environmentally friendly.

Experiments carried out showed that old mixed waste from mining, mineral processing and metallurgy activities worth further studies as secondary raw metals sources.

\section{References}

1. U. S. Geological Survey, Mineral commodity summaries 2021 (U. S. Geological Survey, 2021)

2. European Commission, Study on the EU's list of Critical Raw Materials (2020), Factsheets on Non-critical Raw Materials, (Publications Office of the European Union, Luxembourg, 2020)

3. P. Gu, M. Zheng, Q. Zhao, X. Xiao, H. Xue, H. Pang, J. Mater. Chem. A, 17, 7633(2017)

4. H. F. Fuls, J. Petersen, SAIMM, 13, 423 (2013).

5. Y. Wang, H. Wang, X. Li, C. Zheng, Hydrometallurgy, 195, 105400 (2020)

6. M. A. Bhatti, K. R. Kazmi, A. Ahad, A. Tabassum, R. Mehmood, A. Akram, Pak. j. sci. ind. res. ser. A: phys. sci., 59 (3) 130 (2016)

7. S. Yanbo, T. Xin, Procedia Env. Sci., 31, 195 (2016)

8. J. Frenay, Hydrometallurgy, 15 (2), 243 (1985)

9. L. Wei-zhong, L. Zhuo-yue, Q. Guan-zhou, Q.Wen-qing, Miner. Eng., 20, 694 (2007)

10. S. Ghasemi, S. Mahyar, A. Asghar, Iran. J. Chem. Chem. Eng., 37(5) 105 (2018)

11. M. Ai-yuan, P. Jin-hui, Z. Li-bo, S. Li,Y.g Kun, Z. Xue-mei, Braz. J. Chem. Eng., 33 (4) 907 (2016)

12. A.Y. Ma, L.B. Zhang, J. H. Peng, X. M. Zheng, S.W. Li, K. Yang, W.H. Chen, Green Process. Synth. 5, 23 (2016)

13. S. Yang, D. Zhao, Y. Jie, C. Tang, J. He, Y.Chen, Metals, 9, 83 (2019)

14. N. R. Rodriguez, L. Gijsemans, J. Bussé, J. Roosen, M. A. R. Önal, V. M. Torres, Á. M. Fernández, P. T. Jones, 'K. Binnemans, J. Sustain. Metallurgy 6, 680 (2020)

15. P. Xanthopoulos, S. Agatzini-Leonardou, P. Oustadakis, P. E. Tsakiridis, J. Environ. Chem. Eng., 5, 3550 (2017) 
16. M. I. Muravyov, A. G. Bulaev, T. F. Kondrateva, Minerals Engineering, 64, 63m(2014)

17. Y. Huang, Y. Geng, G. Han, Y. Cao, W. Peng, X. Zhu, T.Zhangc, Z. Dou, J. Hazard. Mater., 389, 122090 (2020)

18. Ma, X. Zheng, S. Li, Y. Wang, S. Zhu, R. Soc. open sci., 5, 180660 (2018)

19. H. Li, L. Zhao, L. Wang, J. Liang, H. Yan, J. Liu, Crystals, 11, 496 (2021)

20. J. V. Mehrabani, S. Z. Shafaei, M. Noaparast, S. M. Mousavi, Int. J. Mining Geo-Eng., 50 (2) 169 (2016)

21. METGROW+ H2020 project, D3.6 Report on metal extraction of low grade ores and wastes (Grant agreement No 690088, Ref. Ares(2018)2258653, 2018).

22. B. Dikhanbaev, C. Gomes, A. B. Dikhanbaev, PLoS ONE 12, e0187790 (2017)

23. Z. Liu, X. Yu, G. Xie, Y. Lu, Y. Hou, E. He, Hydrometallurgy, 125-126, 29-33 (2012)

24. S. Kursunoglu, N. Kursunoglu, S. Hussaini, M. Kaya, J. Clean. Prod. 283, 124659 (2021)

25. J. Xiao, K. Zou, W. Ding, Y. Peng, T. Chen, Metals, 10, 465 (2020)

26. D. Souza, P. S. Pina, F. M. F. Santos, C. A. da Silva, V. A. Leão, Hydrometallurgy 95 , 207(2009)

27. Q. Li, B. Zhang, X.-bo Min, W.-qian Shen, Trans. Nonferrous Met. Soc. China, 232786 (2013

28. S. Aydogan, Chem. Eng. J., 123 (3), 65-70 (2006) doi.org/10.1016/j.cej.2006.07.001

29. O. Adebayo, K. O. Ipinmoroti, O. O. Ajayi, Chem. Biochem. Eng. Q., 17 (3), 213(2003)

30. D. Filippou, Min. Proc. Extr. Met. Rev., 25 (3), 205 (2004)

31. E. A. Abdel-Aal, Hydrometallurgy, 55 (3), 247 (2000) 